\title{
ERRATUM
}

\section{Comparative analysis of panicle proteomes of two upland rice varieties upon hyper-osmotic stress}

Wei HUANG, Ting BI, Weining SUN (凶)

SIBS-UC (Berkeley) Center of Molecular Life Sciences, Institute of Plant Physiology and Ecology, Shanghai Institutes for Biological Sciences, Chinese Academy of Sciences, and Graduate School of the Chinese Academy of Sciences, Shanghai 200032, China

Received June 29, 2010; accepted July 28, 2010

Correspondence: Weining SUN

E-mail: wnsun@sibs.ac.cn

(C) Higher Education Press and Springer-Verlag Berlin Heidelberg 2011

Frontiers in Biology 2010, 5(6): 546-555

A mistake appeared in Figure 2 of Page 549. The figure should be changed to the one below.
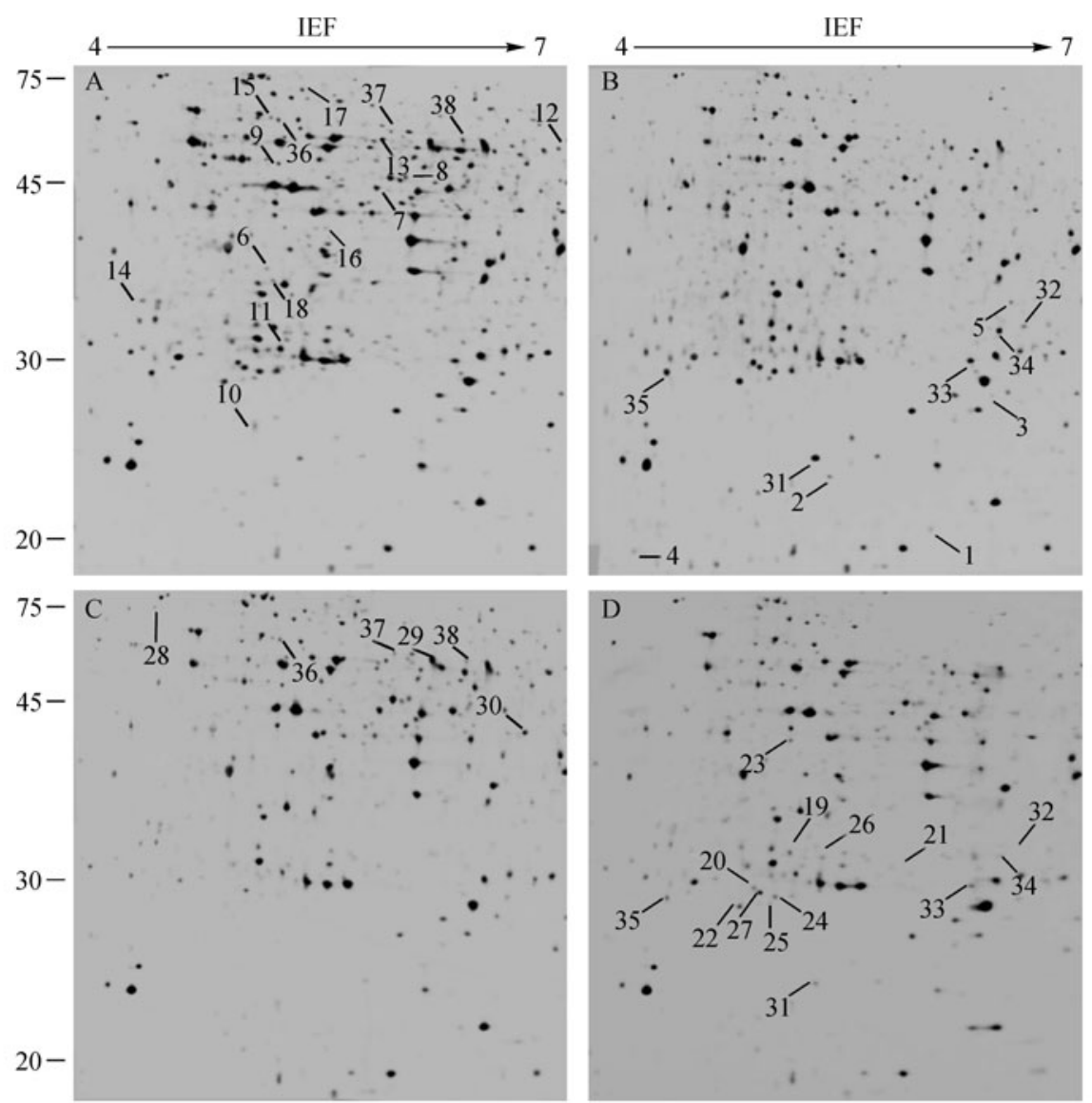

The online version of the original article can be found at http://dx.doi.org/10.1007/s11515-010-0720-3 